\title{
GIS Instruments in Support of the Forestry Activities: A
}

\section{Case Study}

\author{
Gabriele Garnero and Ingrid Vigna \\ DIST-Interuniversity Department of Regional and Urban Studies and Planning, University and Polytechnic of Turin, Castello del \\ Valentino, Torino 10125, Italy
}

\begin{abstract}
Geographic information systems (GIS) are computer systems used to acquire, store, analyze and display of geographical data. They can provide support to the activities of a forestry consortium, which needs to plan its work in relation to the territory it manages. This article will illustrate the case study of the Canavese Forestry Consortium by analyzing the sources of the data it uses and the operations it does with them. Finally, this work will give an insight on further GIS instruments that can be used to support its activity. The activities carried out during the experimentation have entered into the ordinary activities of the consortium, which now uses the technologies described. It is considered that these indications can become patrimony for other similar cases.
\end{abstract}

Key words: GIS, forestry consortium, QGIS2Web, Collector

\section{Introduction}

The first evaluations of the Terzo Inventario Nazionale delle Foreste e dei Serbatoi Forestali di Carbonio (Third National Inventory of Forests and Sink of Carbon) reveal an Italian national forestry surface of 10.9 million hectares, which correspond to the $36 \%$ of the total surface of the country. Moreover, the continuous increase of this surface is evident: it has increased of 600,000 hectares from 2005. These numbers suggest how important the forestry economic sector is, or should be, in the modern society. In fact, the functions of the forest are different: timber production, protection of the soil, ecotourism and recreation, conservation of the biodiversity, regulation of the climate, carbon sequestration and maintenance of an historical and cultural knowledge.

The aim of silviculture is finding a compromise between economic, social and ecologic demands, by using a sustainable management. That means operating in order to preserve and reinforce the future potentialities and services of the forest [1].

Corresponding author: Gabriele Garnero, associate professor, research field: geomatics.
Forest management plans are necessary to reach this objective. They have to be based on the analysis of naturalistic aspects of the territory, of the silvicutural choices made in the past, of the current regulation and of the cultural and economic needs of the area. The analysis needs to take into account goals and targets of the different actors that are involved in landscape planning [2, 3].

The purpose of forest planning is to define territorial policies by imaging its transformation, or its maintenance, in the future, in order to make it more able to carry out one or more functions $[4,5]$.

A cartographic support is essential: representing the territory is necessary for being able to make any decisions, communicate with the exterior and supervise the evolutions caused by interventions [6, 7].

Geographic information systems (GIS) are therefore really useful: they make possible an analysis of geographical data, by spatial modeling and by associating attribute information to the objects. They are a set of computer material, software, data, operator and users that allow integrating information derived from different sources and technologies, such as 
remote sensing and GPS systems [8].

Another important characteristic of GIS, developed from the nineties, is the possibility to share data by the net, allowing a fast exchange at a long distance and optimizing economic resources [9].

The purpose of this article is to analyze how GIS technologies can be used in the silvicultural field, in order to highlight their potentialities and the support they can provide to the growth of the forestry sector. The research will illustrate the case study of the Canavese Forestry Consortium and will give an insight on some powerful geomatic instruments, not yet used at it $[7,10]$.

Once realized the computerized database, are different possible applications ranging from the management to the forest planning up to virtual reality and augmented reality [11].

\section{Materials and Methods}

\subsection{The Canavese Forestry Consortium}

The Canavese Forestry Consortium was established in December 2002, according to the rural development plan (Piano di Sviluppo Rurale) 2000-2006 of the Piemonte region. It was born with the aim to manage the agro-forestry-pastoral territories of the municipalities that weren't able to do it independently. At the moment the associates are the municipalities of Alice Superiore, Brosso, Canischio, Castellamonte, Castelnuovo Nigra, Chiesanuova, Cintano, Colleretto Castelnuovo, Forno Cnavese, Issiglio, Mazzé, Meugliano, Quassolo, Rueglio, Trausella, Traversella, Vico Canavese and Vidracco, the Mountain Community Valchiusella, Valle Sacra, Dora Baltea Canavesana and the agricultural cooperative Valli Unite del Canavese of Castellamonte Vico Engergia s.r.l., for a total surface of 3,500 ha.

The administrative organization of the consortium is consisted by the Shareholders' Meeting and the board of directors that carry out the administrative job. The current president is Antonio Bernini, who represents the municipality of Vidracco.
The consortium doesn't have any employees: both technical and administrative works are assigned to the consultants.

The forestry patrimony of the Canavese is hard to manage, because of its history: it has been deeply destroyed in the past and has been recently abandoned [1]. The main aim of the consortium is to do it protecting natural resources and the landscape, with attention to the hydro-geological aspect. The consortium acts in different fields: economic issues, technical support to the partners for improving the infrastructures, fire prevention, divulgation, research, training and consultation.

The consortium often uses GIS for its tasks and, in particular, it uses the open source software Quantum GIS (QGIS) for:

- Visualizing cartographic material coming from different sources;

- Integrating that information with data acquired on the field;

- Creating new information, thanks to the intersection of the different layers;

- Representing the planned interventions on a map;

- Updating the database with the transformations of the area due to the interventions;

- Monitoring the activity by visualizing the information created.

The consortium database is divided in two fields: one consists of the rough data and the other includes data elaborated for writing the Forestry Business Plan (Piano Forestale Aziendale). The first one includes:

- Regional data, available in raster or vector format. It refers to the Regional Technique Computer Map (Carta Tecnica Regionale Numerica) or to the more modern Banca Dati Territoriale di Riferimento per gli Enti (BDTRE), the cartographic support for the Piedmont region;

- Provincial data, referring to the Provincial Technique Map (Carta Tecnica Regionale), available through the Città Metropolitana web site or the Regional Agency for Environmental Defence web site 
(GeoPortale dell’Agenzia Regionale per la Protezione Ambientale);

- Data shared by the Forestry Regional Informative System (Sistema Informativo Forestale Regionale). It refers to the Forestry Map (Carta Forestale), divided in municipal areas or forestry areas. It gives specific forestry information, such as the forestry type and the location of the seed source woods;

- Cadastral data, available in different formats, provided from the municipalities associated;

- Fieldwork data, acquired with a touristic precision GPS and referring to different aspects of the area, such as the transport links.

The aim of the elaborated data is to create the Forestry Business Plan, which is the main instrument of the forest management planning. The current one was created for a surface of 573.34 ha, included in the municipalities of Alice Superiore, Issiglio, Meugliano, Rueglio, Trausella, Vico Canavese and Vistrorio. It has been approved by Piemonte region on May 13th, 2013 and will last until 2021. It is made by a part of analysis of the territory and the forestry estate and by a part of planning of the interventions. It basically includes a technique report, a detailed description of each parcel and of the interventions related, useful photos of the area and some important cartographic documents. Those documents are the result of the elaboration operated on the rough data, which produced a group of shape files. Each intervention operated is noted on the Interventions and Events Registry (Registro degli Interventi e degli Eventi) and the shape files are constantly updated related to it.

\subsection{GIS Instruments}

GIS instrument can support the activity of the consortium by modalities not yet fully exploited: between them, this article will analyze web map service (WMS), the QGIS plugin QGIS2Web and the app Collector.

\subsubsection{WMS Services}

It is an Open Geospatial Consortium (OGC) standard. OGC is an international non-profit organization for defining free technical specifications for sharing geographical data. WMS is usually used to share maps in raster format, coming from different databases. They can be visualized from the user by a web browser or by a GIS software. It's also possible to visualize more maps at the same time by superposing them, if they are transparent. The user accesses the service by a URL provided by the creator of the map. It includes information about the size of the map, the location of the area represented and the coordinate system employed, in addition to the metadata related.

A lot of geoportals offer WMS services, such as the GeoPortal Piemonte. It also make available by this way many ortophotos, geometrically corrected and georeferenced aerial photos. They have been taken from 2009 to 2011, they are coloured and they cover almost all the surface of the region, using WGS84/UTM zone 32N reference system. They are available just by WMS service and they can be very useful in order to integrate the information of traditional maps with accurate data about, for example, the border of a clearing.

The main advantage of using WMS services is to attain the updated data without the need of downloading periodically the latest version of it. However, they require a high speed internet connection in order not to slow down the operations with the GIS software, because the maps are online visualized. This is a limiting factor for the Canavese Forestry Consortium, because its office is located in a badly served area.

\subsubsection{QGIS2Web}

Sharing data on the internet can be useful also for publishing the consortium ones. QGIS2Web is a plugin developed for QGIS and freely downloadable, which allows transforming a project made by the software on a map sharable on the web. The consortium could use it for sharing maps of the works in progress on its web site. This operation would 
require resources of money and time, also for the constant updating and rationalize of the database, which are often inadequate. However, it could be useful, for example, for managing the announcements.

In order to evaluate the potential of this instrument, a sample web map has been created. It gives information about the lots. The process of creation is shown below:

Firstly, it's necessary to create a QGIS project that includes all the necessary layers. In this case, only the vector layer "attuazione_PFA", which contains the polygons and the information of the parcels, has been used. Then, the proprieties of the project have been changed, in order to select "yellow" as colour for the selections. The proprieties of the layer have also been changed: it has been renamed as "parcels", dark green has been selected as the colour of the polygons and the fields of information shown have been chosen. In this case, they are:

- Number of the forestry area;

- Number of the parcel;

- Forestry type;

- Standing volume;

- Number of plants in 1 ha;

- Basal area;
- Average height;

- Municipality concerned;

- Cadastral surface;

- Potential notes.

By starting the plugin installed, a base map has been chosen (Thunderforest Landscape); ordinary display options are available in this view

Between two available formats, OpenLayers3 has been selected and map has been exported. The result is an html file, which can be open with a web browser (Fig. 1).

As shown in the example, QGIS2Web allows creating a very simple employment map, in which the user can easily find information. It can be attached, for example, to the web site of the consortium with an informative aim. Even though the complexity of the process increases with the number of the layers shown, the process of creation of the map remains easy and fast and doesn't require a complicated training of the operator.

\subsubsection{Collector}

Collector is an application produced by ESRI that allows collecting fieldwork georeferenced data with just a smart phone (Fig. 2).

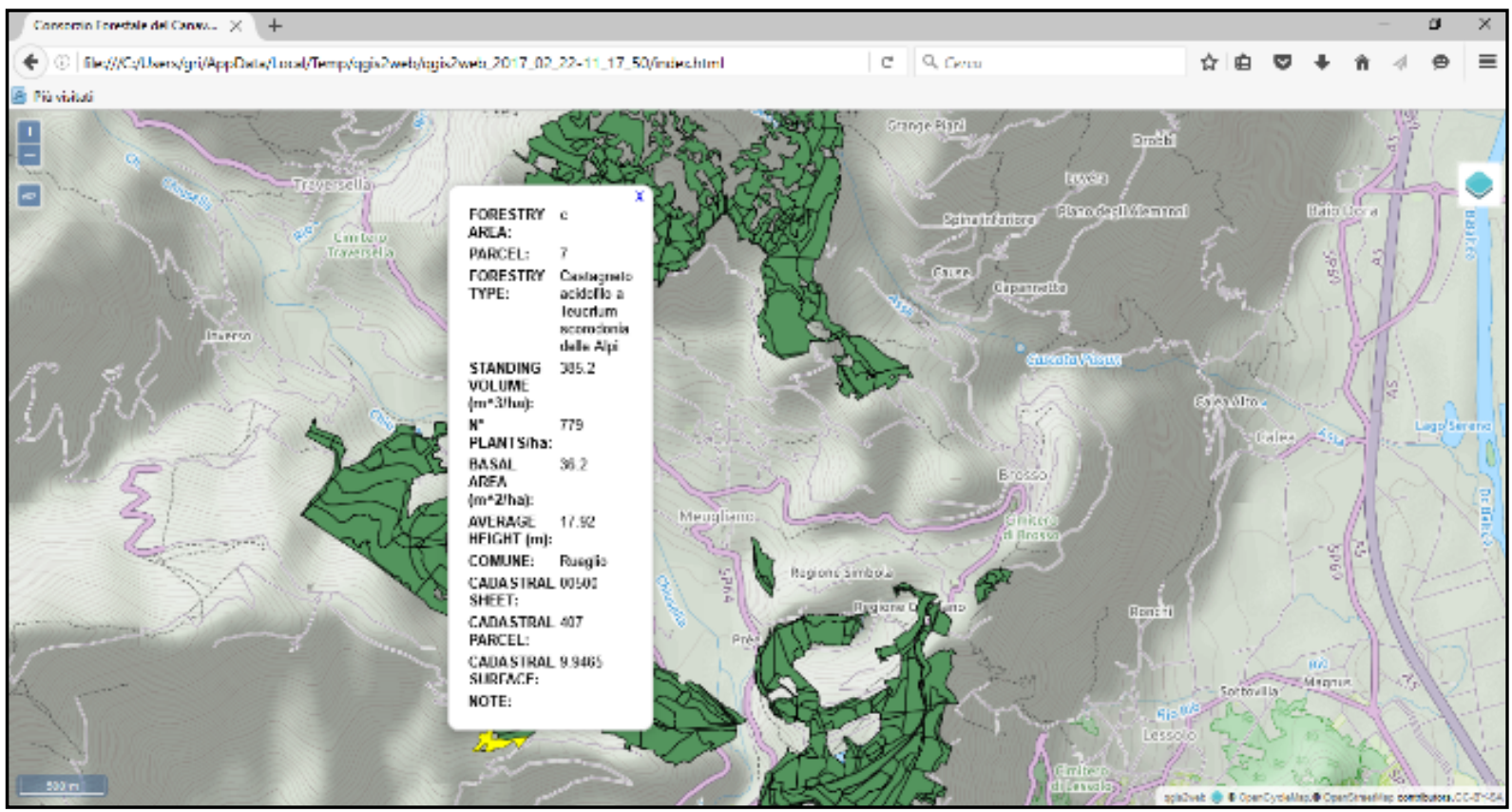

Fig. 1 Html file created with QGIS2Web, with a sectioned parcel. 
First of all, it's necessary to prepare a specific database with ArcGIS for desktop and then it is possible to create a map with ArcGIS online. All the steps are shown below. This example shows a map for collecting information on unstable plants signaled in the territory of the consortium.

The database has to be prepared and domains have to be defined. The domain "risk class" is created. Its kind of field is "text" and its kind of domain is "codify values". These values refer to the risk classification defined by Demetra and are:

- A: no imperfections;

- B: low imperfections;

- C: significant shape and structure imperfections;

- C-D: serious imperfections;

- D: high risk, need of knocking down.
Then, a feature class has been created. That is a container of information with similar characteristics. The fields chosen are (Fig. 3):

- Diameter;

- Height;

- Species;

- Risk class;

- Notes.

The values that can be associated to the first and second fields are numerical, although the others are textual. Moreover, the "risk class" field is associated to the "risk class" domain of the geodatabase. Like this, it can assume only the five values listed previously. Different colors are assigned to the elements, which are geometrically shaped as points, in order to distinguish them based on the class risk.

\section{(1)}

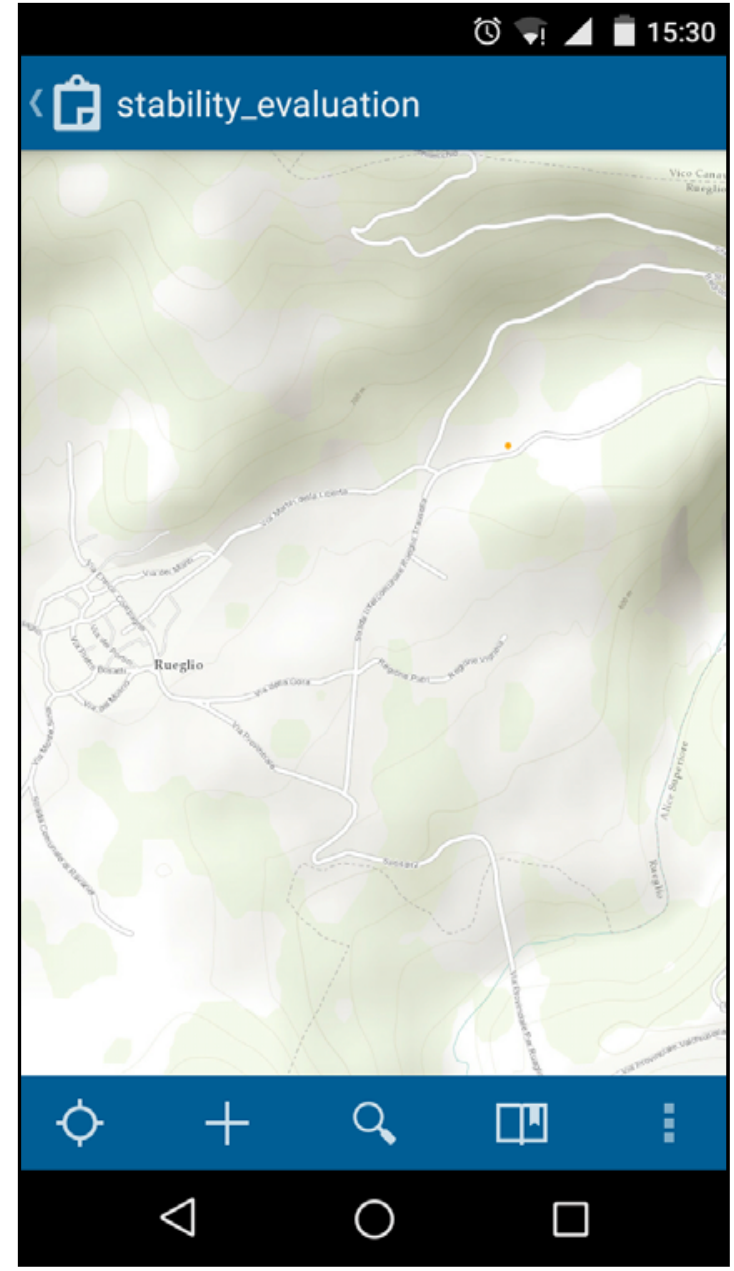

Fig. 2 The map visualized on the smart phone with Collector. 


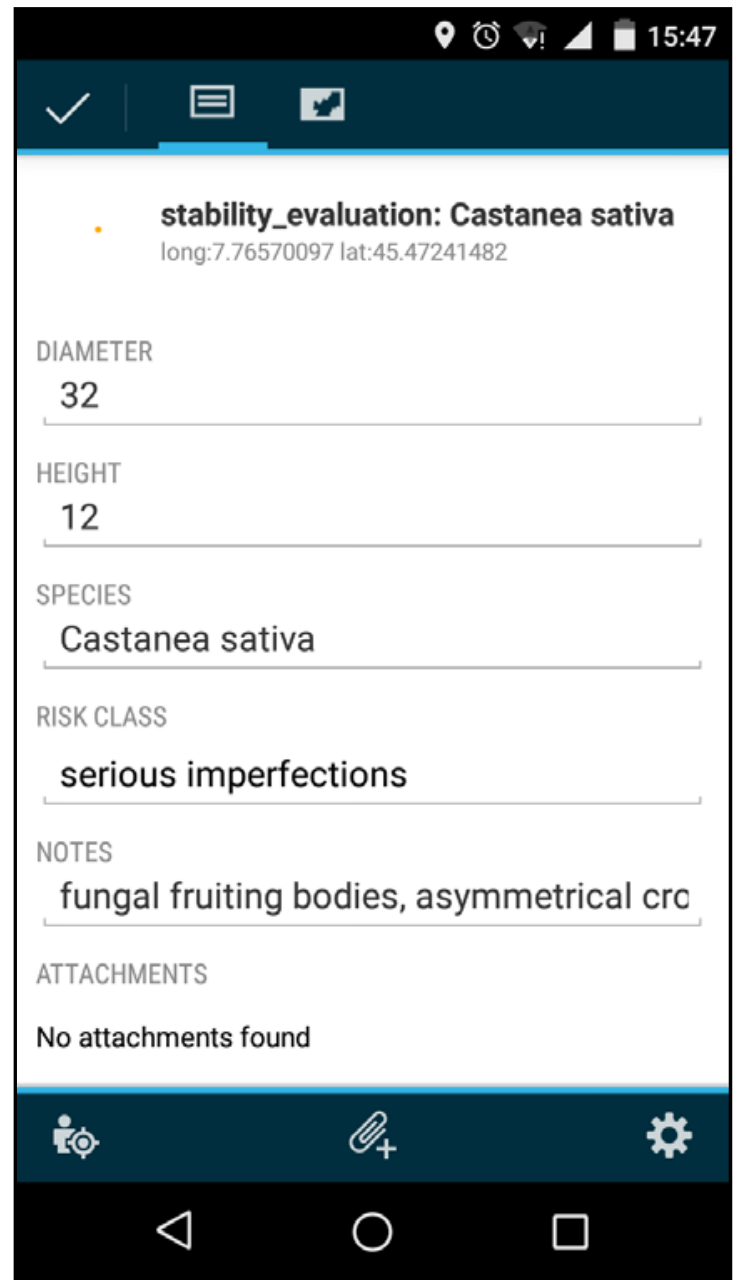

Fig. 3 Example of table visualized on the smart phone.

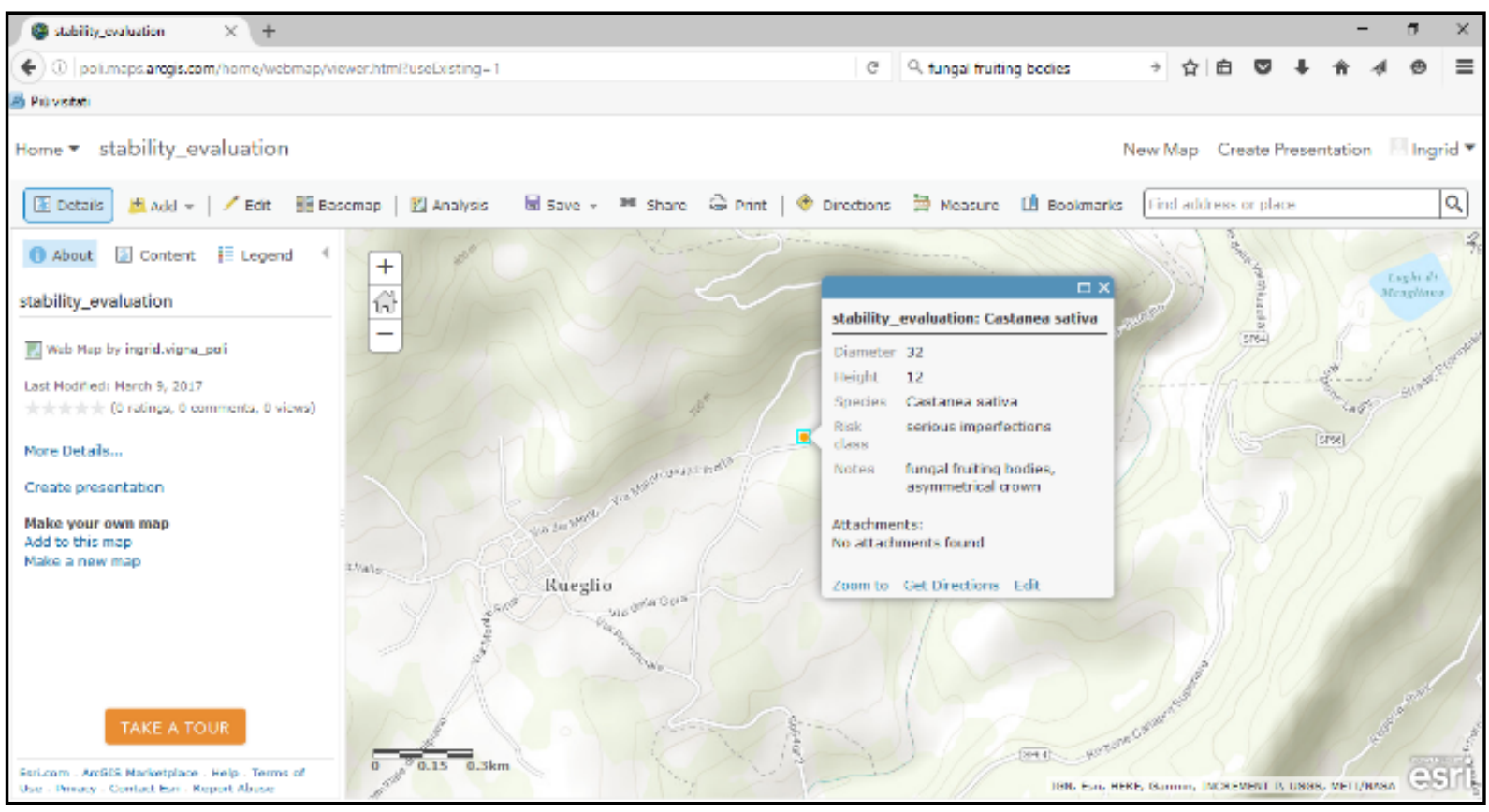

Fig. 4 Collector map for geolocating unstable plants. 
Finally, the possibility to attach photos of the plant to the point during the fieldwork is added (Fig. 4).

It's now necessary to publish the data online, sharing them as a service associated to the own ESRI account for the own organization. In this case, the functions update, create, remove, query and synchronize for the other members of the organization are activated. For sharing the service it's also necessary to add a description of the element, which is "used for geolocate plants with stability problems" in this case and to add some tags, such as plants, stability, evaluation and risk.

The last step is the creation of the map for collecting data with ArcGIS online. A base map has to be chosen, in this case a topographic one and the layers have to be joined, in this case stability-plants-evaluation that correspond to the service published. In the setting, the search by layer is enabled, based on the "species" field, in order to allow the user searching an element knowing the species of the plant signaled.

Now the map is ready and it's possible to add information to it. There are two ways for doing it: by modifying the map with ArcGIS online or using Collector application. All users with an ESRI account joined to the organization, that's consortium employees in this case, can contribute to the geodatabase. By downloading the application on their smart phone, they can move on the land and add elements on the map when they are next to an unstable plant [12].

They visualize a table that they have to fill out with the values corresponding to the feature class. They can also take a photo of an important detail and attach it.

In the following picture is presented the map on ArcGIS online, in which three plants have been geolocated on the territory of Rueglio and Alice Superiore. By a click of the mouse on them, it's possible to read the information associated to them.

\section{Results and Discussion}

The advantages of using Collector instead of a traditional GPS instrument refer to the price of the equipment and to the simplicity of employment. In fact, any specific training of the operators is necessary for collecting data. Moreover, the information is automatically charged on the online database, speaking of which it's also possible to collect the data offline and synchronize them in another moment. This is really important in the forestry field, because operators often work in bad conditions and in marginal areas, without an adequate internet connection [8].

On the other hand, the precision of the smart phones GPS systems is often mediocre. However, the use of a simple smart phone may be sufficient to carry out some tasks such as the one in question, even in view of the ease of use. In fact, any specific training of the operators is necessary for collecting data. Moreover, the information is automatically charged on the online database, speaking of which it's also possible to collect the data offline and synchronize them in another moment. This is really important in the forestry field, because operators often work in bad conditions and in marginal areas, without an adequate internet connection.

Concerning the costs, the necessity of using the paying software ArcGIS instead of the open source one QGIS has to be evaluated. Moreover, the present absence of any employees in the Canavese Forestry Consortium reduces the advantages of Collector.

\section{Conclusions}

The consortium is currently working on applications of the activity described above that involve the use of GIS tools developed in the experimentation.

It is believed that the proposed applications may be useful for applications in similar territories. 


\section{Acknowledgments}

The authors show their thanks to Daniele Poncino, external consultant of the Canavese Forestry Consortium, for his help during the analysis of the activity of the consortium.

\section{References}

[1] Bovio, G., Ceccato, R., and Marzano, R. 2007. "Training Support for Territorial Forest Planning.” Ricerca Forestale. Accessed May 16, 2017. http://www.ricercaforestale.it/index.php?module=CMpro \&func $=$ viewpage $\&$ pageid $=420$. (in Italian)

[2] De Meo, I., Ferretti, F., Frattegiani, M., Lora, C., and Paletto, A. 2013. "Public Participation GIS to Support a Bottom up Approach in Forest Landscape Planning.” iForest: Biogeosciences and Forestry 6 (6): 347-52.

[3] Sonti, S. H. 2015. "Application of Geographic Information System (GIS) in Forest Management." Journal of Geography and Natural Disasters 5 (3): 1-5.

[4] Wachiye, S. A., Ndegwa, D. K., and Musiega, D. 2013. "GIS Based Forest Cover Change and Vulnerability Analysis: A Case Study of the Nandi North Forest Zone.” Journal of Geography and Regional Planning 6 (5): 159-71.

[5] Sajjad, A., Hussain, A., Wahab, U., Adnan, S., Ali, S., Ahmad, Z., and Ali, A. 2015. "Application of Remote Sensing and GIS in Forest Cover Change in Tehsil
Barawal, District Dir, Pakistan.” American Journal of Plant Sciences 6 (9): 1501-8.

[6] Di Bari, C. 2007. "GIS to Support Forest Planning." Ricerca Forestale. Accessed April, 2017. http://www.ricercaforestale.it/index.php?module=CMpro \&func=viewpage \&pageid=259. (in Italian)

[7] Godfrey, P. 2009. “Managing the Urban Forest.” Forestry GIS Journal 1: 6.

[8] ESRI Inc. 2015. "Improving Forest Management Using the ArcGIS Platform." ArcUser 16-7. http://www.esri.com/ /media/Files/Pdfs/news/arcuser/10 15/improving-forest-management-using-arcgis-platform.p df.

[9] Andreopoulou, Z. S. 2011. "Introducing Computer and Network Services and Tools in Forest Service and the Human Resources Factor.” Journal of Environmental Protection and Ecology 12 (2): 761-8.

[10] Tasoulas, E., Varras, G., Tsirogiannis, I., and Myriounis, C. 2013. "Development of a GIS Application for Urban Forestry Management Planning.” Procedia Technology 8 70-80.

[11] Garnero, G., Corrias, A., Manigas, L., and Zedda, S. V. 2013. "VGI, Augmented Reality and Smart Web Application: Projects of Development in the Territory of the Sardinia Region.” In International Conference on Computational Science and Its Applications, Heidelberg: Springer, 77-92.

[12] Ballauri del Conte, I. 2011. 2011-2021 Corporate Forest Plan of the Canavese Forest Consortium. Technical Report. (in Italian) 